\title{
VULNERABILIDADES Y OPRESIONES DE GÉNERO EN LAS MIGRACIONES INTERCONTINENTALES DE MENORES ${ }^{1}$ \\ VULNERABILITY AND OPPRESSIONS OF GENDER IN CHILD INTERCONTINENTAL MIGRATIONS
}

\section{Esther Torrado Martín-Palomino²}

\section{Resumen}

Las diferencias de género que se dan en las migraciones de personas que entran de forma irregular en España procedentes de África, se producen tanto en origen, como en trayecto o destino. En el caso de las migraciones de menores que viajan sin el acompañamiento de un tutor legal, tienen una estrecha vinculación con las redes de tráfico y trata de seres humanos. Son migraciones donde los fuertes controles a su movilidad y los castigos de género, constituyen una eficaz y lucrativa escuela de desigualdad migratoria. A través de esos castigos (que buscan la ejemplaridad, el desempoderamiento y la sumisión) mayoritariamente de centralidad sexual, traficantes y proxenetas obtienen importantes beneficios. Son una útil herramienta que funcionará a la perfección, mediante una ajustada selección de la víctima (mujer, joven, pobre e irregular) y un continuum uso de las violencias.

Palabras claves: Género, menores no acompañados, irregularidad, migraciones, invisibilidad, tráfico y trata de seres humanos.

\begin{abstract}
Gender differences that occur in migrations of people entering illegally in Spain from Africa, occurring both in origin and in route or destination. In the case of migration of children traveling unaccompanied by a legal guardian, have a close connection with the networks of trafficking in human beings. They are migrations where strong controls to their mobility and punishments gender, are an efficient and lucrative School immigration inequality. Through these punishments (seeking exemplary, disempowerment and submission) majority of sexual centrality, traffickers and pimps profit immensely. They are a useful tool that will work seamlessly through a tight selection of the victim (female, young, poor and irregular) and use a continuum of violence.
\end{abstract}

Keywords: Gender, unaccompanied minors, irregularity, migration, invisibility, trafficking and human smuggling

\footnotetext{
${ }^{1}$ Este artículo forma parte del Proyecto I-D “Justicia, ciudadanía y género: Feminización de las migraciones y derechos humanos" del Ministerio de Economía y Competitividad del Gobierno de España.

2 Profesora-Investigadora del Departamento de Sociología y Antropología; Universidad de la Laguna, Tenerife. España. Miembro del IUEM (Instituto Universitario de Estudios de las Mujeres). E-mail: estorra@ull.edu.es
} 


\section{INTRODUCCIÓN}

Las migraciones de Menores Extranjeros No Acompañados (a partir de ahora MENA) constituyó un fenómeno novedoso en España en las últimas décadas del siglo XX y principios del XXI. Específicamente en las islas canarias, frontera sur intercontinental entre África y Europa, se comenzó a observar a partir del año 1996, fecha exacta en la fue interceptada una "patera" con un menor de origen marroquí a bordo ${ }^{3}$. Aunque en sus inicios eran mayoritariamente varones jóvenes del norte del Magreb los protagonistas de estos flujos ${ }^{4}$, en la actualidad los perfiles han ido variando en cuanto a procedencias y género, comenzándose a detectar menores de origen subsahariano, con una mínima presencia de mujeres jóvenes y niñas. A pesar de compartir características comunes con las migraciones de MENA en otros territorios de España, en Canarias se observan marcadas diferencias; son mayoritariamente de origen africano (en otros territorios existe la presencia de flujos procedentes del este) paterizadas y con una estrecha vinculación con las redes de tráfico y trata de seres humanos, sin la cual no podrían superar la peligrosa travesía del atlántico ${ }^{5}$ (Torrado y González, 2009). Desde ese significativo año en el que se intercepto la primera patera con un MENA a bordo y hasta la actualidad, la variabilidad en cuanto a número y perfiles ha venido auspiciada entre otros, por las diferencias de estándares de vida, la proximidad territorial de las costas, la influencia de las redes migratorias y las TIC, así como las restrictivas leyes migratorias europeas que han limitado (mediante una fuerte vigilancia fronteriza) la accesibilidad de personas adultas al territorio Shengel ${ }^{6}$. Pero a pesar que estas condiciones de desigualdad son mayores en mujeres y niñas migrantes (tanto en origen como en destino) su presencia es minoritaria en España, debido a los fuertes controles a su movilidad existentes en sus sociedades con importante influencia patriarcal en normas y tradiciones. No obstante, es preciso enfatizar en el hecho, de que a pesar de ser migraciones minoritarias, presentan importantes novedades en los patrones y estrategias de movilidad que son escasamente estudiadas. El desconocimiento no sólo

\footnotetext{
${ }^{3}$ En España el término patera se refiere a las pequeñas embarcaciones de material precario, cuyo uso es el traslado y acceso clandestino de migrantes africanos a las costas del Estrecho de Gibraltar, el Mar Mediterráneo por Andalucía o el Océano atlántico a las Islas Canarias.

${ }^{4}$ Se denomina Magreb a la región del Norte de África que comprende los países de Marruecos, Túnez, Argelia, Mauritania, Sáhara Occidental y Libia.

${ }^{5}$ Torrado E. y González, A. 2009. "Una aproximación al tráfico y contrabando de personas: el caso diferencial de menores, niños y niñas en España”. Revista Atlántida, vol. oㅣ, 37-63.

${ }^{6} \mathrm{El}$ territorio Schengen suprime fronteras interiores entre Estados con una única frontera exterior para controles de entrada. Pertenecen todos los Estados miembros de la Unión Europea, excepto terceros países como Islandia, Liechtenstein, Noruega y Suiza. Por otra parte no todos los países de la Unión Europea pertenecen a Schengen como Reino Unido e Irlanda.
} 
se debe a la escasa representación estadística sobre el conjunto de las migraciones, sino a los espacios de vulnerabilidad e invisibilidad donde se gestan y a la escasa tradición de investigar con perspectiva de género. Por ello la invisibilidad no es sólo resultado de esa condición de migrante clandestino y del propio género, sino de la tendencia dominante en el estudio de las migraciones a externalizar resultados de mayorías significativas (y evidentemente las jóvenes y niñas MENA no lo son). También la escasa tendencia a aplicar en investigación perspectiva de género, produce déficits en el conocimiento de las migraciones que se alejan de los patrones tradicionales migratorios. Estos se pueden observar en el contexto español de forma tangible, cuando se consultan fuentes secundarias de estudio, donde a pesar de existir prolíferos estudios sobre MENA en España, es escasa y limitada la información sobre las singularidades de mujeres jóvenes y niñas?

Por estas razones es especialmente relevante, analizar estas singularidades de las niñas entre fronteras desde la perspectiva de género, puesto que aún no siendo representativas, deben ser consideradas conforme al artículo 3 del Protocolo contra el Tráfico ilícito de migrantes por tierra, mar y aire (Jefatura del Estado, 2000) no sólo menores en riesgo (por no estar acompañadas de tutor legal y ser irregulares) sino víctimas del tráfico personas por ser trasladadas e introducidas en un país de forma irregular y sobre todo niñas tratadas por su forzado destino, la explotación sexual y laboral mayoritariamente. En ese sentido, este artículo refleja a través de la investigación con menores que entran de forma irregular a España sin un tutor que les acompañe, esas diferencias de género existente en origen, trayecto y destino y la inexorable vinculación de las niñas al tráfico pero sobre todo a la trata, donde los fuertes controles a su movilidad y autonomía, constituyen una eficaz y lucrativa escuela de desigualdad migratoria y donde a través de castigos de género de centralidad sexual mayoritariamente (matrimonios forzados, de honor, violaciones individuales o colectivas, obligación a prostituirse, abortos clandestinos y mutilaciones genitales femeninas) se conforma la perversa pero útil herramienta para los traficantes de personas, con importantes resultados de desempoderamiento y sumisión de sus víctimas y una repercusión no

7 En más de 15 años de experiencia en investigación de las migraciones de MENA africanos hacia las Islas Canarias principalmente y hacia España por parte de la autora de este artículo, han sido anecdóticas y puntuales las ocasiones donde se ha hallado algún estudio que observe esas diferencias o al menos las mencione, a pesar de ser vox pópuli entre los profesionales que intervienen en el proceso de interceptación y protección ( policía, trabajadores sociales, Juzgados, Consulados) que las niñas solas entre fronteras, presentan modelos esos novedosos de movilidad intrafronterizos, con estrategias de selección, supervivencia diferenciales en origen, trayecto y destino y con costes mayores por la extrema dureza y violencias de las que son objeto por ser menores y niñas. 
sólo en su dignidad como mujer y en sus derechos y libertades, sino en los costos y resultados migratorios ${ }^{8}$ (Torrado, 2012).

\section{MIGRACIONES DE MENORES SOLOS: INTERSECCIONANDO PERFILES Y VISIBILIZANDO EL GÉNERO}

Uno de los cimientos iniciales en los se fundamentó este trabajo, procede del estudio sobre Menores Extranjeros No Acompañados en Canarias ${ }^{9}$ (Barroso et al, 2006) realizado por un equipo de investigadores/as de la Universidad de la Laguna bajo encargo técnico del Gobierno de Canarias y en plena Crisis de los Cayucos del 2006 en Canaria. Ese año constituyó un antes y un después en la realidad social de Canarias, obligando a las administraciones gubernamentales a improvisar un sistema de gestión y atención de migrantes procedentes de África que produjo un cierto temor social desproporcionado a una "supuesta invasión" y "generó en Canarias una situación de emergencia humanitaria de jóvenes subsaharianos principalmente que dejaron sus vidas en el mar debido a los naufragios causados por la conjunción entre la fragilidad de las embarcaciones, el mal tiempo y las traicioneras corrientes marinas"10 (Guerra, 2013). Un importante número de menores, quedaron bajo la tutela de las instituciones de protección, facilitando así la localización para su estudio, de un colectivo que por su alta movilidad y su condición de clandestinidad siempre presentó dificultades. Por ello el trabajo de campo se realizó mediante entrevistas amenores residentes en los centros de acogida de Canarias ${ }^{11}$, para conocer sus perfiles sociodemográficos, sus proyectos migratorios y de acogida, así como las expectativas de futuro, pudiendo cuantificar y caracterizar a los MENA interceptados por el sistema de

\footnotetext{
${ }^{8}$ Torrado Martín Palomino, E." La inmigración de menores desde la perspectiva de género. Revista Dilemata № 10, pp-65-84, 2012.

${ }^{9}$ Barroso, C. et al. "Análisis de los Menores Extranjeros No acompañados en Canarias" Informe realizado para la Viceconsejería de Asuntos Sociales e Inmigración del Gobierno de Canarias, 2006.

${ }^{10}$ Guerra, M.J. "Fronteras y migraciones. La crisis de los cayucos en las Islas Canarias y la ceguera del liberalismo igualitarista". Revista Dilemata, № 12, pp 63-74, 2013.

${ }^{11}$ En el año 2006 no sólo hubo una entrada masiva de MENA a todas las islas (hasta ese momento habían accedido a las islas orientales de Lanzarote y Fuerteventura de forma escasa e intermitente) sino que cambió el perfil de los migrantes (principalmente del Sahel con la aparición de niñas) el tipo de embarcación (los popularmente denominados cayucos que son embarcaciones de grandes dimensiones con destino a la pesca típicas de Senegal), con un alargamiento de las rutas y el consecuente empeoramiento de las condiciones físicas de los migrantes a su llegada (antes salían del norte de África y a partir de ese año mayoritariamente de Senegal) y con penetración en todas las islas (incluidas las islas occidentales y las pequeñas islas de La Gomera, El Hierro que no disponían de recursos de acogida). Ello obligó a improvisar un macrocentro de menores en La Montañeta, que genero múltiples problemas con vecinos de pueblos cercanos que verbalizaron su rechazo y políticos entre la administración autonómica canaria que exigía respuestas inmediatas y el gobierno de España (Millet, 2006, Agencia Efe, 2006, Rodríguez Borges, 2010).
} 
protección de menores y contrastar las diferencias con los de otros territorios de España. Tras el desarrollo de ese trabajo y la emisión del precitado informe, el equipo investigador observó la escasez de datos e informaciones sobre las niñas MENA. Esta escasa representación no sólo generaba invisibilidad en su estudio, sino desigualdades en el establecimiento de recursos para su protección, reflejados en la carencia de centros especializados para su atención y mayores déficits en la recogida de datos sociodemográficos ${ }^{12}$, lo que dificultaba más aún su caracterización y conocimiento $^{13}$. Ante esto, se planteó continuar realizando prospecciones sociales, eso sí, esta vez exclusivamente a jóvenes y niñas MENA con perspectiva de género y aunque se encontraran fuera de los circuitos de protección. Las múltiples dificultades para acceder a las propias MENA, con una alta incidencia en fugas y una dispersión en diversos centros generalistas de acogida, hizo que se recurriera a mediadores o facilitadores para la contactación con mujeres de origen subsahariano (por ser mayoría en los flujos de niñas MENA en Canarias) y que arribaron al archipiélago siendo menores, pero que o bien no fueron interceptadas por las Fuerzas y Cuerpos de Seguridad del Estado o se fugaron de los Centros de menores o cumplieron la mayoría de edad. Estas entrevistas se realizaron dentro de los proyectos I+D "Poblaciones y Mercancías: Tráfico de mujeres y niñas en España"14 (López et al, 2007) y “Justicia ciudadanía y género: la feminización de las migraciones"15 (Guerra et al, 2013) permitiendo establecer un marco interpretativo de diferencias inéditas.

\section{AMARRES ENUNCIATIVOS Y VINCULACIÓN DE LAS MIGRACIONES DE MENORES CON EL TRÁFICO Y TRATA DE SERES HUMANOS}

En el desarrollo del trabajo de campo con MENA en Canarias, y la consulta de fuentes secundarias, se observaron similitudes y homogenización de perfiles, con cierta saturación de información en los discursos. Casi el 100\% de los menores eran varones, africanos y con escasas

\footnotetext{
${ }^{12}$ En la Comunidad Autónoma Canaria en esos años se estableció un sistema de protección de MENA para su recepción y atención, dotándolo de recursos como los centros de emergencia (CAI) y una red de centros de atención a menores extranjeros no acompañados (CAME). Sin embargo las niñas que eran interceptadas, se las acogía en centros generalistas de menores con diversas problemáticas o situaciones de riesgo, en muchos casos de dependencia religiosa.

${ }^{13}$ Es en esa época también cuando el Gobierno de Canarias, establece una base de datos Ilamada IM (Inicial de Menores) que más que un instrumento de estudio de los perfiles de MENA, era una base de control de entradas y salidas del sistema de protección de menores. No obstante en muchos casos, permitía recoger datos sociodemográficos de procedencia, edad, estudios.

${ }^{14}$ López, A et al. "Proyecto I+D. Poblaciones y mercancías: tráfico de mujeres y niñas en España". Ministerio de Igualdad, Gobierno de España, 2007.

${ }^{15}$ Guerra, M.J. et al. "Proyecto I+D. Justicia, ciudadanía y género, feminización de las migraciones y derechos humanos. Ministerio de Economía y Competitividad. Gobierno de España, 2013.
} 
diferencias en cuanto a la edad. Una de las diferencias se dio en los/as MENA de origen subsahariano, que en el momento de su interceptación. Algunos iban acompañados de un adulto que declaraba ser familiar. Estos hechos han sido denunciados públicamente por diversas ONG como Médicos sin Frontera, Cruz Roja, que consideran una nueva estrategia de penetración fronteriza utilizada por las redes de tráfico y trata de seres humanos (Coordinadora de Barrios et al, 2005) para vulnerar el sistema de protección y detección de menores solos. Constituye un resquicio permeable de tráfico de migrantes africanos/as que se hacen pasar por familiares cuando en realidad son pasantes o tratante. Otra tipología de MENA son los originarios del Magreb, que si bien inicialmente son captados por redes de tráfico para su traslado, no se constata que sean objeto de trata antes durante lo que no les exime que en destino y por las precarias condiciones de vida, acaben corriendo el riesgo de ser objeto de explotación laboral e incluso sexual. Éstos menores, buscan mayoritariamente incorporarse al mercado laboral (aunque sea de forma irregular) y reagruparse con familiares residentes en España o Europa. Cuando son interceptados declaran ir sin compañía de tutor legal (aunque frecuentemente viajan con primos, paisanos o grupo de iguales) y habitualmente se declaran menores de edad (lo sean o no) para evitar la repatriación, teniéndose que enfrentar a las dudosas pruebas de determinación de la edad, mediante el test oseométrico ${ }^{16}$, el cual determinará su posibilidad de permanecer en el territorio bajo la tutela del Estado, si se confirma esa minoría de edad, que en España está determinada hasta el cumplimiento de los 18 años.

Sobre las condiciones de los trayectos y el viaje suele haber escasa información, pero la disponible nos revela que son originarios del Magreb y que suelen partir rumbo a Canarias desde el Aaiún en pequeñas embarcaciones de no más de 20 personas. Con cierta frecuencia recurren a la estrategia de declararse saharauis, con el objeto de recibir un trato especial como asilados y refugiados políticos (aunque en la mayoría de los casos son hijos de colonos marroquíes). Generalmente suelen desconocer el lugar desembarco y el tiempo de travesía, aunque la media (si no existen complicaciones) es de 24 a 36 horas. A este tiempo debe añadirse para el caso de los

16 La minoría de edad se determina con el test oseométrico, consistente en una radiografía del brazo izquierdo. Si se confirma el MENA pasa a ser tutelado por el sistema de protección español y en un plazo no mayor de 9 meses tal y como establece la ley, a un permiso de residencia. Tanto el test como los plazos de regularización, han sido denunciados por ONG de derechos humanos, al considerar las pruebas poco fiables y que no deben realizarse si se acredita mediante documentos la edad. Con respecto a los plazos de obtención de residencia legal, se ha denunciado que se incumplen con frecuencia aduciendo colapso del sistema, lo que produce que muchos menores ante la falta de residencia legal, el cumplimiento de la mayoría de edad y el miedo a la expulsión, opten por fugarse de los centros y permanecer de forma clandestina en el territorio. 
migrantes del Sahel, el empleado en atravesar las fronteras interiores del continente africano y el de estancia precaria en los campamentos fronterizos de Marruecos. Para la mayoría Canarias es sinónimo de Madrid, Barcelona, Sevilla o cualquier gran ciudad y Europa representa la vida de la gran ciudad. Pero al desembarcar en las costas canarias perciben que las islas están a más de 3000 kilómetros de ese objetivo, separado además por una segunda frontera administrativa y geográfica, la del peligroso Océano Atlántico y la necesidad de identificación documental para acceder al territorio peninsular español, lo que les genera una situación de shock. De aquellos escasos menores que reconocen haber pagado a las redes para su traslado a España y se atreven a dar información, afirman que entregaron a los traficantes unos 2.176 dírham marroquíes (unos 200 euros) aunque persiste el tabú de aportar este tipo de datos sobre formas de contactación e información de las redes de tráfico. En el caso de los migrantes subsaharianos, nos consta que al ser más largas las rutas se incrementan los costos, pudiéndose establecer un precio en metálico, en especie (como en el caso de las mujeres obligadas a prostituirse) o bajo aval de propiedades de las familias, superando en muchos casos los 20,000 euros y que pueden incluso ir incrementándose en función de los intereses marcados por los prestamistas. En cualquier caso, existen reticencias en aportar información sobre cuestiones referentes a los pagos y las redes, ya sea por miedo a las represalias o por precaución para no aportar información en muchos casos sobre vecinos y familiares que pueden estar implicados dentro de ellas. No existen reticencias a aportar información sobre sus expectativas y proyectos migratorios, mayoritariamente de centralidad económica y que se gestan con el consentimiento familiar (lo que les hace depositarios de las esperanzas de mejorar su calidad de vida). En cuanto a la naturaleza de los proyectos de acogida e inclusión que ofrecen las instituciones, los MENA suelen presentar un importante desconocimiento, a pesar de que su futura integración está en juego (González y Torrado, 2008) ${ }^{17}$. Las instituciones de protección suelen orientar sus intervenciones al cuidado personal y la formación reglada, lo que no se ajusta a las expectativas de los MENA y sus familias que desean obtener ingresos para mejorar su calidad de vida, máxime cuando han arriesgado sus propias vida para ello o el escaso patrimonio familiar ${ }^{18}$ (Barranco et al,2007)

\footnotetext{
17 Gonzalez, I. y Torrado, E. "Frente a Frente: Proyectos educativos y proyectos migratorios de menores extranjeros no acompañados en Canarias”. Revista Quirriculum, vol. 21, pp-37-63, 2008.

18 Barranco, C. et al. "Investigación sobre los menores extranjeros no acompañados en Tenerife. Una aproximación a sus proyectos migratorios y educativos". En La Inmigración irregular en Tenerife (Godenau, D y Zapata, V. coord.) Cap.7, p-p 281-321, Tenerife, 2007.
} 
“Nos obligan a estudiar porque no tenemos edad española para trabajar. (...). Cuando tenemos la edad no nos dan papeles para poder trabajar, esto es un mal sueño". EM4-2. (Entrevista realizada a MENA hombre del Magreb).

Las expectativas de futuro son las de conseguir un empleo a corto plazo, ahorrar dinero y mandar remesas a la familia, no planteándose el retorno definitivo a su país de origen. El discurso generalizado de estos menores esta articulado en el fracaso y miedo al futuro, por no haber podido cumplir sus expectativas migratorias, además de la carga psicológica que supone ser testigo de experiencias muy traumáticas antes y durante su trayecto migratorio así como de los futuros escenarios de vulnerabilidad a los que están expuestos tras abandonar los Centros de Acogida ante el cumplimiento de la mayoría de edad con el objeto de evitar la expulsión (González y Torrado, 2008)

"Después de cuatro años aquí, saldré sin nada, sólo a esperar que la policía me eche de aquí." EM4-2 (Entrevista realizada a MENA hombre del Magreb).

Junto al peso de las duras condiciones y experiencias migratorias, está el de ser portadores de las esperanzas de mejora de la calidad de vida de sus familias y los efectos de las malas prácticas e incumplimientos del sistema de protección. Ello les situará en un inexorable escenario de riesgo, sea en solitario o como consecuencia de la relación con las redes de tráfico y trata, relegándoles a espacios y actividades clandestinas. En teoría la minoría de edad constituye una ventaja para acometer los proyectos migratorios con cierto éxito, dado que existen menores posibilidades para su expulsión del país, pero en la práctica, la minoría de edad se torna en un factor de vulnerabilidad y exclusión. La imposibilidad de cumplir sus expectativas migratorias, los relega al círculo de la pobreza y la falta de oportunidades. La preocupación de las instituciones por impedir el efecto llamada, utilizando prácticas de gestión dilatorias, les aboca a la fuga de los centros antes de la mayoría de edad y en condiciones de clandestinidad. En Canarias por esas especiales condiciones geográficas, definidas por la fragmentación de su territorio y la insularidad, los menores que acceden de forma clandestina al territorio, deben hacerlo a través de travesías marítimas controladas por redes de tráfico y trata. Aquí la improvisación y autonomía es imposible, dado que es preciso contar con apoyo económico e infraestructura para acometer con cierto éxito el proyecto migratorio, por lo que existe la alta probabilidad de que el menor se incorpore en destino a las estructuras mafiosas de las redes y sus actividades ilegales, si fracasa en la consecución de sus expectativas migratorias. 


\section{INVESTIGACIÓN CON PERSPECTIVA DE GÉNERO COMO NECESIDAD PARA VISIBILIZAR LA REALIDAD DE LAS NIÑAS}

En el estudio de las migraciones de niñas solas a través de fronteras transnacionales, aparecen tres elementos claves para su (re) conocimiento: la escasa representación en estudios cuantitativos que no contemplan las interseccionalidades de género, la invisibilidad de los espacios donde se las confiere y el androcentrismo en la ciencia y las políticas sociales. Estos elementos, así como las múltiples opresiones de las que son objeto, produce un oscilante vapuleo a sus derechos humanos "como humanas" que influirán en su estudio y las intervenciones de los agentes y agencias del control de las migración, llevándose a la máxima expresión el dicho de lo que no se ve, no existe y por tanto no constituye un problema. Por ello, la invisisibilidad constituye uno de los mayores problemas en su estudio, que no solo es de tipo cuantitativa sino de sus realidades interseccionales. Su escaso peso estadístico en la generalidad de los movimientos migratorios de MENA y la ausencia de una perspectiva de género en los estudios de las migraciones internacionales clandestinas, las confiere a una nueva y añadida indefensión, generando nuevas brechas de género en sus resultados migratorios, con menos posibilidades de éxito y con más violencia. Es preciso resaltar que de los MENA interceptados en Canarias en el año 2006 el 9\% de eran niñas y de ellas el 67\% eran del Sahel ${ }^{19}$ (Barroso et al, 2006) ${ }^{20}$.

Como se ha apuntado con anterioridad, existen otras dificultades para su estudio, que derivan del déficit de datos de las niñas interceptadas por los sistemas de protección así como de la recogida de información en los instrumentos de las instituciones gubernamentales, que en su mayoría desconocía en el $18 \%$ de los casos, el lugar y fecha de llegada y en el $82 \%$ la generalidad de los datos necesarios para el conocimiento de sus perfiles sociodemográficos ${ }^{21}$ (Barroso et al, 2006). Con respecto a la invisibilidad de las niñas, derivada de los espacios donde son conferidas, se observó que a pesar de ser mayoritariamente del Sahel y con rasgos etnoraciales visibles, ocupaban nulos espacios de visibilidad pública a su llegada a las islas. Esta escasa presencia en espacios públicos, así como la inexistencia de recursos especializados para su atención, marca diferencias con respecto a los niños MENA. Las niñas cuando son interceptadas, se integran en

\footnotetext{
${ }^{19}$ La zona del Sahel africano está delimitada al norte por el Sahara y al sur por la sabana. Conforma los países de Senegal, Chad, Mauritania, Mali, Níger, Nigeria, Camerún. Gambia, y Burkina Faso.

20 Barroso, C. et al. "Análisis de los Menores Extranjeros No acompañados en Canarias" Informe realizado para la Viceconsejería de Asuntos Sociales e Inmigración del Gobierno de Canarias, 2006.

${ }^{21}$ Barroso, C. et al. "Análisis de los Menores Extranjeros No acompañados en Canarias" Informe realizado para la Viceconsejería de Asuntos Sociales e Inmigración del Gobierno de Canarias, 2006.
} 
centros de protección generalistas, suelen ser de dependencia privada e incluso religiosa y conviven con menores con problemáticas variadas. La inexistencia de centros especializados para ellas, podría constituir una cierta vulneración a los derechos de igualdad, derivados de una inversión en recursos diferencial con respecto a los varones MENA 22.

Las edades de las niñas migrantes que viajan solas, cuando son interceptadas por los Cuerpos y Fuerzas de Seguridad del Estado en frontera, oscila entre los 16 y 18 años (ligeramente superior a los MENA hombres). Este dato tiene relación con el origen, mayoritariamente del Sahel, lo que implica que aunque abandonan sus aldeas a edades más tempranas, tienen que recorrer largas y múltiples fronteras interiores (a veces a pie) hasta el punto de embarque con destino a Europa, invirtiendo una media de entre uno (en el mejor de los casos) y tres años. Otra de las diferencias con respecto a los niños, son las opresiones de género y las violencias de las que son objeto en los trayectos, siendo sometidas con mayor frecuencia a retenciones contra su voluntad y a múltiples tipos de violencia, tanto por parte de los miembros de las redes como de sus compañeros de viaje. Estas violencias en forma de castigos de género, son parte de una ideología del desempoderamiento y sumisión que mediante el miedo, consigue garantizar la mercancía y los beneficios (mayoritariamente del negocio de la prostitución)

"Salí de mi aldea con 13 años acompañada de un amigo de mi familia que prometió buscarme trabajo en Europa. Atravesamos juntos dos países a cambio de favores sexuales. Llegué a los campamentos de Marruecos con 15 años. Allí otro hombre ocupó su lugar y me dijo que le llamara papá, después de obligarme a prostituirme y pegarme violentamente si me negaba. Al llegar a Canarias mi "padre" y yo fuimos detenidos y tras pasar por un centro, nos expulsaron sin papeles. Ahora es mi jefe en esto de la prostitución, aunque mi familia no sabe nada". EMA5-1. (Entrevista realizada a MENA mujer del Sahel).

En las migraciones de estas mujeres hacia Canarias, se observa nuevas estrategas de las redes de tráfico y trata y que en caso de las niñas MENA, constituye elementos adicionales de invisibilidad y vulnerabilidad (por ser menor, mujer y clandestina). Ésta consiste en la suplementación de roles, donde los adultos que las acompañan se hacen pasar como padres,

\footnotetext{
22 Durante el año 2007 realizando el proyecto I+D "Poblaciones y mercancía. Inmigración y tráfico de mujeres y niñas en España", financiado por el Ministerio de Igualdad, se visitó el Centro Maternal de Tenerife, donde se encontraban acogidas menores embarazadas o lactantes de nacionalidad española y extranjera. Pese a disponer de los permisos pertinentes del Cabildo Insular de Tenerife para acceder a las instalaciones, no se pudo realizar ninguna entrevista directamente a menores de origen africano, ofreciéndose información de las mismas por parte de los/as profesionales de dicho centro.
} 
hermanos o incluso parejas de la futura mujer embarazada o de sus niños/as de temprana edad (en muchos casos como resultado de violaciones en los trayectos). Con esta estrategia evaden los controles de las instituciones de protección al menor, o aminoran el mismo, siendo reconocidas como MENA pero no víctimas de trata o mujeres acompañadas. Esto podría dejar de ser "la tubería que gotea" con la realización de pruebas genéticas y medios profesionales necesarios en frontera, evitándose la exposición de estas menores a esa doble desprotección muy relacionada con la trata y donde al no ser declaradas como MENA (por estar acompañadas de adultos o supuestas parejas) se las deja en manos de tratantes o explotadores que nunca van a cumplir con el objetivo de la protección de esa menor ${ }^{23}$. Ello debe llevar a las instituciones y profesionales a plantearse la propia (re)construcción de la desprotección y sus protocolos de actuación, actualmente centrados en la minoría de edad y en el no acompañamiento de tutor legal en el momento de su interceptación, y que no contemplan el hecho que ese "supuesto acompañamiento" no es garantía de derechos y dista mucho del ideal de protección de la infancia. Lo cierto es que sean MENA o niñas acompañadas de forma inadecuada, son objetivo primordial para ejercer la violencia (mayoritariamente sexual), por partir de condiciones de vulnerabilidad y que generarán múltiples espacios de desprotección sobrevenida en el destino.

Otro aspecto novedoso en el análisis, es el referido a la diversificación de espacios donde son conferidas, que tienen relación con la procedencia y la etnoracialidad. Habitualmente el destino de las mujeres jóvenes y MENA del Magreb, suelen ser la reagrupación familiar, el trabajo doméstico o los matrimonios concertados. Presentan diferencias con respecto a las procedentes del Sahel, ya que suelen ser objeto de menor violencia, puesto que son conferidas a espacios de menor vulnerabilidad, sus trayectos son más cortos y gozan de cierta protección de las redes de tráfico y los patrones de las embarcaciones que en muchos casos son paisanos ${ }^{24}$ (Torrado, 2012)

"Las mujeres marroquíes son pocas en las barcas, pero a ellas se las respeta más porque los dueños son paisanos, son blancas y vienen a España a casarse o a limpiar. " EMA5-2. (Entrevista realizada a MENA mujer del Sahel).

Esta diversificación de espacios que tienen relación con la procedencia y la etnoracialidad, se refleja el IV Informe del Ministerio de Sanidad, Política Social e Igualdad (2011) donde la policía

23 La versatilidad de los tratantes y el conocimiento que tienen de los procedimientos policiales, ofrece seguridad en los traslados de las mercancías, máxime cuando no se contempla en frontera la realización de pruebas de paternidad/ maternidad que acrediten el vínculo y prevengan una habitual y nueva estrategia de tráfico y la trata de niñas.

24 Torrado Martín Palomino, E." La inmigración de menores desde la perspectiva de género. Revista Dilemata no 10, pp-65-84, 2012. 
alertaba de la situación de las niñas subsaharianas, que con frecuencia se las destinaba a la explotación sexual, debido a las condiciones de vulnerabilidad, edad, características físicas y étnicas y la demanda de los prostituidores "en relación con las mujeres en las que se han detectado signos de trata, el $44 \%$ contaban entre 26 y 35 años, siendo Nigeria uno de los principales países de origen de dichas mujeres. En el 57\% de las 199 denuncias realizadas, las posibles víctimas tenían entre 18 y 25 años, y 13 se corresponden a posibles víctimas menores de edad"25 (Ministerio de Sanidad, Política Social e Igualdad, 2011). En cualquier caso, sean conferidas a espacios domésticos o de explotación laboral o sexual, estas jóvenes permanecen en ellos con escasas posibilidades de interacción con el medio, de información sobre sus derechos y bajo la tutela y control de un varón (sea pareja, proxeneta o ambos a la vez). Por ello sus condiciones en las migraciones clandestinas son de mayor riesgo y precariedad, al estar en contacto con las redes internacionales de tráfico y trata de seres humanos, que ejercen un fuerte control en origen, garantizando una mercancía dócilizada mediante la selección de niñas en extrema necesidad y el ejercicio de la violencia. Esto, junto a los factores que propician la doble vulnerabilidad (ser menores y traficados) garantizan la proliferación y beneficios de esta práctica criminal de naturaleza internacional.

Circunscribiéndonos a las Islas Canarias, la existencia de una indisoluble relación entre migraciones africanas irregulares y el negocio del tráfico y trata de seres humanos, no sólo tiene que ver con las políticas de control fronterizo, o de cercanía de costas, sino por la selección de migrantes vulnerables como mercancía altamente rentable, y los menores lo son y mucho. El aumento de la demanda en las sociedades occidentales de mercancía joven y vulnerable con destino a la explotación sexual, ofrece un buen caldo de cultivo para el lucro de este complejo entramado internacional en aumento, sin embargo el abordaje sociológico, criminológico, normativo y de intervención social resulta proporcionalmente más complejo, precisamente por esas circunstancias de mayor vulnerabilidad que le rodean: son menores de edad y objeto de un estatus especial de protección y su irregularidad les circunscriben a medidas legales y sociales que hacen más compleja sus realidades

"Cuando salí de mi aldea era una niña. Todo el viaje lo tienes que hacer acompañada de un hombre y tienes que elegir entre ser agredida por los pasantes o por los propios compañeros. Ninguna mujer puede viajar sin compañía”. EMA5-5 (Entrevista realizada a MENA mujer del Sahel).

\footnotetext{
${ }^{25}$ Ministerio de Sanidad, Política Social e Igualdad. "Informe ejecutivo del V informe anual del Observatorio Estatal de Violencia sobre la Mujer". Disponible en htttp://www.msssi.gob.es/ssi/violenciaGenero/publicaciones/observatorioestatalVM/Informes.
} 
Por ello es necesario identificar y conocer cómo afecta esta práctica criminal del tráfico y la trata a las niñas y su fuerte impacto. El actual marco legal de protección y sus protocolos de intervención, no las contemplan prioritariamente como víctimas de trata sino como MENA, por lo que es necesario ampliar y trascender esa conceptualización de la protección de los menores solos o inadecuadamente acompañados, ya que los actuales procedimientos están más centrados en la identificación del menor y su tutela que en el tratamiento de las consecuencias de tiene ser víctima de trata siendo menor y su protección (exista o no denuncia) ya que se en el caso de las niñas, sus vulnerabilidades y las violencias de las que son objeto, se diluyen en sus situaciones de clandestinidad, incluso como se ha mencionado, en el caso de las subsaharianas, que a pesar de esos visibles rasgos etnoraciales, la minoría de edad y la situación de irregularidad, resultan más impermeables a los controles fronterizos y su interceptación como víctimas de trata

“Entré por Canarias, tras un viaje de tres años. Ahora me encuentro en Andalucía y cuando pague mi deuda quiero ir a Francia, donde tengo familia. Estuve en un centro donde cuidaron de mí y mi hijo. En poco tiempo volví con mis paisanos a hacer lo que tenía que hacer. " (EMA5-5, entrevista a mujer MENA del Sahel)

Y es que la actividad delictiva de la trata, no solo se genera en las fronteras europeas sino en las africanas y donde las razones para el tráfico de menores es mucho más variadas y donde los procesos de clandestinidad y el hecho de que se produzcan en el seno de las propias familias, hacen más imperceptible el problema. El conocimiento se suele nutrir de la información de los sistemas policiales o de protección de cada país, por lo que la información y su acceso, dependerá del nivel de corrupción de los propios sistemas y de la efectividad de los controles fronterizos que pueden estar centrados en la protección a la víctima y persecución de las mafias o la lucha y disuasión de la migración clandestina. También como se apuntó con anterioridad, la invisibilidad estadística y del conocimiento del fenómeno, dificulta el diseño de estrategias de denuncia y abordaje de la problemática específica de las niñas MENA. De hecho, en el caso de España y particularmente en Canarias, el protocolo de actuación para los/as MENA, produce otros efectos negativos que deberían ser tomados en consideración, ya que a pesar de ser interceptados en frontera y entrando de forma irregular mediante su traslado (muchas veces forzado) no prima el procedimiento la consideración prioritaria de ser víctima de trata por encima de la de MENA, que les garantizará su permanencia en España hasta la mayoría de edad, pero que les hará seguir siendo objetivo del control de las mafias, por no tener un estatus especial de protección. Esto junto a las especiales y diferentes condiciones en las que viajan con respecto a los adultos, les hace estar 
mucho más expuestos a situaciones de vulnerabilidad. Los/as protagonistas cruzarán, desde un primer momento, fronteras interiores y exteriores sin acompañamiento de un tutor legal o con un adulto que puede ser su pasante o proxeneta, en situaciones de extrema dureza física y emocional. Muchos de ellos han sido forzados a prostituirse, mendigar o cometer delitos como denunció la Organización para la Seguridad y la Cooperación en Europa ${ }^{26}$ (OSCE, 2008) que estimaron la existencia de 20.000 menores en España que eran víctimas de explotación, así el progresivo incremento en los últimos años. También es cierto que algunos/as estudiosos/as del tema, recomienda no vincular estas migraciones clandestinas con el fenómeno de la trata de mujeres, puesto que no todas las personas traficadas están destinadas a la explotación sexual ${ }^{27}$ (Mena y González, 2008), aunque en el caso de las niñas subsaharianas, todo apunta a ello, ya que el género, la edad y la procedencia, constituyen factores de vulnerabilidad determinantes, siendo una de las actividades que más crece en la Unión Europea, siendo la mayoría de las víctimas mujeres y de ellas el $50 \%$ niñas.

\section{CARTOGRAFÍAS DE LAS MIGRACIONES DE NIÑAS: PROYECTOS Y MOTIVACIONES}

En el desarrollo de los proyectos y expectativas migratorias de las niñas, las interseccionalidades convergentes, constituyen a su vez múltiples elementos de vulnerabilidad que van a influir negativamente en la consecución de sus objetivos. Así los costes migratorios son mayores que en los niños, tanto en lo material como en lo personal. En sus trayectos migratorios y a través de castigos de género, se llevarán a cabo la instrumentalización de todo tipo de actos de control y violencia y que producirá situaciones de sumisión e indefensión. Estos castigos de género se articulan fundamentalmente en el ejercicio de la violencia física-sexual ejemplarizante, justificándose culturalmente, en el necesario control a la movilidad de las mujeres que deben ejercer las sociedades altamente patriarcales, máxime en las migraciones, donde las mujeres han tenido un papel secundario y subordinado a los proyectos de los hombres y la familia. En el caso de las migraciones transnacionales, el protagonismo ha sido masculino, y las mujeres eran relegadas a proyectos de reagrupación o matrimonio. Por ello las que migran en solitario, ya sea de forma

\footnotetext{
${ }^{26}$ OSCE (Organización para la Cooperación y Seguridad en Europa). "Informe anual sobre las actividades de la OSCE", 2008. Disponible en http://www.osce.org/es/secretariat/36702?download=true

${ }^{27}$ Mena, L y González, A. "Como medir el fenómeno de la trata y el contrabando de mujeres en destino, con las fuentes de datos existentes en España". En Violencias contra las mujeres (Merino, R y Martínez, E. coord.), 2008. Revista Estudios Interdisciplinares de género. Centros de Estudios de la Mujer de la Universidad de Salamanca.
} 
voluntaria (con proyectos de autonomía o de huida de las leyes patriarcales) o de forma forzada, se alejan del paradigma tradicional de "la buena mujer". También en comunidades tradicionales las migraciones de niñas, a pesar de constituir una estrategia de supervivencia de las propias familias, no cuenta con el beneplácito de la comunidad y se las castiga por ello, ya sea en los trayectos, como en los países de destino o si se produce la repatriación o retorno, en cuyo caso es prácticamente imposible la aceptación de su comunidad y de su propia familia, que lo considerará un deshonor.

"Es el precio que tenemos que pagar por no hacer lo que le corresponde a una mujer." EMA5-3 (Entrevista realizada a MENA mujer del Sahel).

Cada circunstancia a la que deben enfrentarse las niñas, debido a su posición en la estructura social, se añade la de afrontar la migración o la incorporación a un desconocido mercado laboral. Con habitualidad, se suele ignorar estas situaciones problemáticas a las que se enfrenta la población migrante en general y las niñas en particular y su consideración prioritaria condición de víctimas de las redes y objeto de múltiples violências.

“Al llegar a España nadie me pregunto por qué estaba embarazada o que había pasado. Me cuidaron a mí y mi hijo y nada más." EMA5-2 (Entrevista realizada a MENA mujer del Sahel).

Estas interseccionalidades, ayudan a visibilizar las múltiples opresiones que modelan las relaciones sociales en las niñas, tales como el racismo, la etnicidad, el género, la nacionalidad o la religión o la propia clase social ${ }^{28}$ (Hill Collins, 1990:92, Crenshaw, 1991). Estos sistemas de opresión social actúan de forma interrelacionada, donde la discriminación como se ha ido viendo, no solo procede de la pobreza, sino de ser mujer, menor e irregular, siendo acumulativa en el origen, trayecto y destino y por tanto en la consecución de sus expectativas migratorias ${ }^{29}$ (Gimeno, 2013). Así, mientras en los niños varones son mayoritariamente de centralidad económica, en las niñas aparece con mayor frecuencia la centralidad de "agencia" con elementos de autonomía y oposición a los mandatos patriarcales de sus sociedades de origen (matrimonios de honor, ablación).

Salí por mi voluntad. No quería casarme con un viejo amigo de mi tío. En el camino encontré un hombre que se ofreció a acompañarme y hacer de protector. La realidad fue otra. Me golpeaba si no quería tener relaciones con más hombres o no le hacía la comida a él y su grupo. EMA5-3. (Entrevista realizada a MENA mujer del Sahel).

\footnotetext{
${ }^{28}$ Hill Collins, P y Andersen, M. Race. Class and Gender. An Anthology Belmont: Wadsworth Publisher, 1992. Crenshaw, K. W. "Mapping the Margins: Intersectionality, Identity Politics and Violence against women of color". Stanford Law Review, vol 43, p-p 1241-1299, 1991.

${ }^{29}$ Gimeno, C. "Expectativas de acogida en el imaginario de los menores que migran solos". Revista REID, № 9, 2013.
} 
En el estudio de las múltiples formas de opresión de las que son objeto y la intensidad con la que se percibe esa opresión, se ha observado en los menores varones de origen marroquí, una menor percepción de la opresión, posiblemente derivada de ser objeto de menor violencia en los trayectos, no permanecer bajo situaciones de trata en los destinos y de un contar con mayor apoyo social y familiar. De hecho cuando verbalizan sus temores y peligros, éstos se circunscriben al viaje a bordo de la embarcación (hacinamiento, mareas, interceptación policial) o al futuro (por no poder cumplir con sus objetivos y las exigencias familiares

Mis padres me ayudaron económicamente y depositaron sus en mí. Hice lo que tiene que hacer un hombre, ayudar a los suyos. El trayecto fue duro y el trabajo duro pero lo peor el viaje en barco, vómitos, frio, calor y muerte. EMA4-1. (Entrevista realizada a MENA hombre del Magreb).

Sin embargo las niñas (mayoritariamente de origen subsahariano) la sensación de miedo, es percibida antes, durante y posteriormente a su traslado, es decir en todo el proceso migratorio y tiene relación con las violencias que se ejercen contra ellas (mayoritariamente física y sexual) más que con las condiciones del traslado o el futuro- Es cierto que habitualmente los niños cuentan con apoyo social y familiar a través de recursos afectivos y económicos. Ellos han sido elegidos por criterios tribales: son hombres, jóvenes, sanos y con mayores posibilidades de éxito, constituyendo un novedoso rito hacia la adultez y además no son objeto de tantas y tan múltiples violencias como en el caso de las niñas, con opresiones expresadas en un contínuum de violencias contra ellas.

\section{DILOGÍAS DE LAS MIGRACIONES DE NIÑAS: EL NO ACOMPAÑAMIENTO VERSUS LA TRATA}

No es una cuestión baladí decir que el tráfico y trata de niñas existe en Canarias, pero lo difícil es identificarlo y organizar la protección de sus víctimas. Estos niños y niñas son prácticamente invisibles para los Estados, a pesar de que se estima que alrededor de 1,2 millones cada año en el mundo son objeto de explotación sexual ${ }^{30}$ (Save the Children: 2008). Una de las mayores dificultades para dimensionar el problema (mayoritariamente en las niñas) es la diversificación de la demanda y la oferta de la mercancía. Las mafias han pasado a adquirir un nivel de versatilidad tan amplio, que manejan prácticas muy diversas para vulnerar los controles fronterizos, también la tardía incorporación de España a los procesos de migración transnacional (pasando de ser un país de emisión y tránsito de la migración a ser un país de destino) así como su

30 Save the Children. "Esclavos puertas adentro. Las peores formas de trabajo infantil doméstico" 2008.Disponible en www.savethechildren.es/docs/.../Informe_esclavos_puertas_adentro.pdf 
escasa experiencia en la gestión de estos procesos, ha dificultado la propia identificación del fenómeno ${ }^{31}$ (Informe de la Embajada de Estados Unidos en España, 2009). Algunos menores (especialmente los niños) viajan clandestinamente en "pateras" hacia Canarias, ya sea por propia voluntad o con el apoyo de familiares, lo que no conlleva a situación de trata pero sí de tráfico. Por ello cuando llegan al destino, pueden disfrutar de cierta autonomía con respecto a las redes, a no ser que debido a las circunstancias de exclusión, sean nuevamente captados por ellas e incorporados a sus actividades ilegales. Otros menores (especialmente las niñas) aunque viajen por propia voluntad y tengan el apoyo de sus familias e incluso documentación "legal", al llegar al destino son objeto de trata con fines de explotación sexual. Por tanto las niñas y jóvenes tienen mayor riesgo de ser tratadas y son más impermeables a los controles fronterizos que en muchos casos al ser interceptadas por las Fuerzas y Cuerpos de Seguridad del Estado, no suelen identificarlas como víctimas de trata o las propias víctimas no suelen denunciar por miedo a las consecuencias para ellas y sus familias y a la escasa confianza que les genera nuestro propio sistema de protección. La escasez de recursos especializados de tipo técnico, material y humano y las inadecuadas intervenciones jurídico-administrativas y asistenciales, dificultan su abordaje desde la perspectiva de género y los derechos humanos. También la falta de cooperación de las propias víctimas, en ofrecer información, genera nuevas estructuras de indefensión y vulneración de sus derechos, invisibilizando una realidad cada vez mayor por clasificaciones erróneas o incompletas. Por otra parte en la gestación y desarrollo de este fenómeno, existen convergencias entre las distintas categorías de menores migrantes, especialmente en las víctimas de trata y tráfico. Muchos de los/as menores inician su viaje en una categoría y acaban siendo víctimas de otra. Es el caso de los/as menores del Sahel y en especial las niñas que pueden ser traficadas simplemente y convertirse en tratadas y forzadas a la esclavitud y servidumbre, para poder pagar el elevado precio del traslado hasta España:

Desde que salí de mi pueblo no sólo tuve que trabajar en cocinar y limpiar sino prostituirme para poder afrontar los gastos de los pasantes. Dejé de pasar miedo en el momento que subí en la barca. Allí no podía sufrir más. (EMA5-3, entrevista a mujer MENA del Sahel).

Se trata de un viaje costoso en cuanto a esfuerzos, tiempo e incertidumbres y en muchos casos y a pesar de la financiación de la familia, el dinero resulta insuficiente, teniendo que completarlo con otras fuentes de financiación. Es ahí donde entra el "juego" de la trata en personas que aparentemente no han sido obligadas a migrar. Muchas de las niñas y mujeres

${ }^{31}$ Embajada de Estados Unidos en España. "Informe sobre el tráfico de personas en España", 2009. Disponible en http://spanish.madrid.usembassy.gov/es/ru/relaciones/informes/trafico2009.html 
jóvenes, temen denunciar la explotación que sufren por miedo a ser arrestadas o deportadas a sus países de origen, dado que la vuelta puede conllevar a ser objeto de daños irreversibles sobre ellas o sus familias mediante el ejercicio de la violencia, el vudú u otras formas de coerción psicológica o social:

Sé que nunca podré regresar a mi pueblo. Salí siendo una niña y por rechazar lo que me estaba predestinado. Eso en mi cultura significa estar muerta. Negarme a ello e irme es una deshonra. (EMA5-3 entrevista a mujer MENA del Sahel)

La aplicación inmediata de la ley del menor cuando son interceptadas y su tutela, así como el excesivo celo en la protección de sus datos, genera que la información se diluya en la generalidad de las estadísticas migratorias, resultando compleja establecer una cifra fiable de personas traficadas y tratadas que cruzan nuestras fronteras, pierden la vida en ellas o se quedan atrapadas, así como las circunstancias en las que se producen estos traslados y el fin de los mismos

Entré embarazada a España, como consecuencia de violaciones múltiples. Tuve un niño al que acabe queriendo. Me amenazaron con robármelo si no hacia lo que ellos querían. (EMA5-4, entrevista a mujer MENA del Sahel).

A pesar de las múltiples dificultades de carácter metodológico y la oposición de algunos estudiosos, resulta difícil en el caso que nos ocupa, no vincular este tipo de migraciones, al tráfico y trata de seres humanos. Así el Alto Comisionado de las Naciones Unidas para los/as Refugiados ${ }^{32}$ (2007) estimó que este tipo de migraciones se incrementó en un 145\% del año 2002 al 2007 y donde la mayoría de los desplazados fueron mujeres y niñas en condiciones de extrema vulnerabilidad, derivadas de la pobreza, la guerra y las persecuciones étnicas, religiosas o de género en sus países de origen. Otras organizaciones como Save the Children ${ }^{33}$ (2008) denunciaron la situación de desprotección de los/as menores, afirmando que entre 40.000 y 50.000 de ellos, eran objeto de trata para la explotación sexual. También UNICEF ${ }^{34}$ (2005), en su campaña contra el tráfico de seres humanos, afirmó que la mayoría de las víctimas eran niñas. Sus múltiples discriminaciones las sitúa en graves riesgos de sufrir abusos, violencias y explotación sexual. Las estimaciones que se hacen sobre África son especialmente alarmantes "Muchísimos niños y niñas son víctimas del tráfico en África del Oeste y Central, principalmente, para trabajo doméstico pero

\footnotetext{
${ }^{32}$ Alto Comisionado de las Naciones Unidas. "Manual de lucha contra la trata de personas". Disponible en http/7www.unodc.org/pdf/Trafficking_toolkit_Spanish.pdf

${ }^{33}$ Save the Children. "Esclavos puertas adentro. Las peores formas de trabajo infantil doméstico" 2008. Disponible en www.savethechildren.es/docs/.../Informe_esclavos_puertas_adentro.pdf

${ }^{34}$ UNICEF. "El tráfico de personas especialmente de mujeres y niños de África Occidental y Central. 2005. Disponible en http://www.unicef.es/actualidad-documentacion/noticias/el-trafico-de-personasespecialmente-mujeres-y-ninos-en-africa-cen
} 
también para la explotación sexual, para trabajar en tiendas o granjas, etc. Casi el 90\% son niñas." 35 (UNICEF, 2010). La invisibilización mediática y jurídica, el neoliberalismo transnacional que santifica la ley de la oferta y demanda (y que en el caso de los migrantes se centra en su vulnerabilidad) son algunas razones para que se produzca y especialmente en el caso de las niñas. También la estrecha relación con los procesos de globalización, la influencia de las TIC y el incremento de la presión fronteriza en otros territorios, los diferentes estándares de vida entre continentes y la lucha por la supervivencia de los/as más vulnerables del planeta con el desarrollo de múltiples estrategias.

\section{CONCLUSIONES}

En este artículo y partiendo del conocimiento general de las migraciones de MENA, se ha analizado desde la perspectiva de género, las opresiones de las niñas africanas que migran hacia Canarias. Estas menores ofrecen importantes diferencias tanto en los proyectos migratorios, como en sus resultados, lo que constituye un nuevo perfil de migraciones de menores (principalmente del Sahel africano) con la aparición de casos cuyos proyectos migratorios son de centralidad emancipadora o de huida de las estrictas normas patriarcales, además de los habitualmente económicos.

Aunque este tipo de migraciones son minoritarias y la visión androcéntrica de la ciencia las ha obviado, presentan novedades muy relevantes que conviene analizar. Estas menores son sometidas desde el inicio de sus trayectos migratorios a condiciones de mayor dureza y violencia, fundamentalmente por el hecho de ser mujeres y trasgredir la norma patriarcal de la movilidad transmigrante. Por ello se aplicarán marcados castigos de género cuyo fin será adoctrinarlas y desempoderarlas. Estos castigos físicos y sexuales buscarán la ejemplaridad colectiva. Las niñas con proyectos migratorios variados en cuanto a su centralidad, obtienen los mismos resultados, violencia y captación de las redes de tráfico y trata, mediante engaño y coacción. Sin embargo aunque niñas y niños están en condiciones de vulnerabilidad, las posibilidades de éxito de las primeras son menores debido a una mayor intensidad y frecuencia de la violencia y del control a su movilidad. Aunque uno de los objetivos de estos menores, es el de la supervivencia mediante la obtención de medios económicos y autonomía, en las niñas opera la resignación ante un destino lleno de violencias y sumisión, consecuencia del adoctrinamiento iniciado en origen y trayectos con resultados de desempoderamiento. Por ello es importante desarrollar mecanismos de detección y

35 UNICEF. "Sueños de bolsillo". Informe realizado por IFAM, Fundación Pere Ferrer. 2010. Disponible en http:// www.unicef.es/sites/www.unicef.es/files/suenos_de_bolsillo.pdf 
atención a las víctimas, más allá de su consideración de menor no acompañado y que incorpore los elementos de vulnerabilidad y violencia añadida por el hecho de ser mujer e intervenciones coordinadas de los diversos agentes, estrechando los niveles de cooperación que ofrezcan la visualización de realidades que actualmente se tienden a naturalizan y neutralizan como si de algo ajeno y excepcional se tratara, lo que constituye uno de los errores más frecuentes de los Estados que con sus intervenciones parciales y asistencialistas no abordan el "nudo gordiano" y contribuyen a incrementan los espacios de vulnerabilidad y desprotección social de sus víctimas .

\section{BIBLIOGRAFÍA DE REFERENCIA}

AGENCIA EFE. "Continúa imparable la avalancha de cayucos", 2006. Diario el Día. 24.

BARRANCO, C. et al. "Investigación sobre los menores extranjeros no acompañados en Tenerife. Una aproximación a sus proyectos migratorios a los educativos de centros". Godenau D, y Zapata V. (coords) La Inmigración Irregular, Cap. 7, 281-321, Tenerife, 2007, Cabildo Insular de Tenerife, Área de Desarrollo Económico.

Análisis de los Menores Extranjeros No Acompañados en Canarias, 2006. Informe realizado para la Viceconsejería de Asuntos Sociales e Inmigración del Gobierno de Canarias y Fundación Canaria Empresa Universidad por contrato suscrito el 26-12-2005.

CRENSHAW, K.W. Mapping the Margins: Intersectionality, Identity Politics, and Violence against Women of Color, 1991. Stanford Law Review, vol. no 43, 1241-1299.

EMBAJADA DE ESTADOS UNIDOS EN ESPAÑA. Informe sobre el tráfico de personas en España, 2009. Disponible en http://spanish.madrid.usembassy.gov/es/ru/relaciones/informes/trafico2009.html

GIMENO, C. "Expectativas de acogida en el imaginario de los menores que migran solos" 2013. Revista REID, no 9.

GONZÁLEZ, I. y Torrado, E. "Frente a frente: Proyectos educativos y proyectos migratorios de menores extranjeros no acompañados en Canarias", 2008. Revista Qurriculum, vol. 21, 37-63.

GUERRA, M.J. "Fronteras y migraciones. La crisis de los cayucos en las Islas Canarias y la ceguera del liberalismo igualitarista", 2013. Revista Dilemata, no 12, 63-74.

Proyecto I-D Justicia, ciudadanía y género, feminización de las migraciones 2013. Ministerio de Economía y Competitividad. Gobierno de España.

HILL COLLINS, P. y Andersen M. Race, Class and Gender: An Anthology. 1992, Belmont: Wadsworth Publisher.

LÓPEZ, A. et al. Proyecto Poblaciones y Mercancías: Tráfico de mujeres y niñas en España, 2007. Ministerio de Igualdad, Gobierno de España. 
MÉDICOS SIN FRONTERAS. Violencia, vulnerabilidad e inmigración. Atrapados a las puertas de Europa, $2013 . \quad$ Disponible en http:/www.atrapadosenmarruecos.org/doc/informemarruecos2013_cast.pdf

MENA, L. y González, A. "Cómo medir el fenómeno de la trata y el contrabando de mujeres en destino con las fuentes de datos existentes en España", 2008. En Merino, R. y Martínez, E. (coord). Violencias contra las mujeres. Estudios interdisciplinares de género. Centro de Estudios de la Mujer Universidad de Salamanca.

MILLET, D. "Bienvenidos a la Montañeta. No los queremos aqui", 2006. Diario La Opinión de Tenerife, 1-4

MINISTERIO DE SANIDAD, Política Social e Igualdad. Informe ejecutivo del V informe anual del observatorio Estatal de Violencia sobre la Mujer, 2011. Disponible en htttp://www.msssi.gob.es/ssi/violenciaGenero/publicaciones/observatorioestatalVM/Informes

ALTO COMISIONADO DE NACIONES UNIDAS, 2007. Manual de lucha contra la trata de personas. Disponible en http/7www.unodc.org/pdf/Trafficking_toolkit_Spanish.pdf

ORGANIZACIÓN PARA LA COOPERACIÓN Y SEGURIDAD EN EUROPA (OSCE). 2008. Informe anual sobre las actividades de la OSCE. Disponible en http://www.osce.org/es/secretariat/36702?download=true

RODRÍGUEZ BORGES. R.F. El Discurso del miedo. Inmigración y prensa en la frontera sur de la Unión Europea, 2010. Plaza y Valdés, Madrid.

SAVE THE CHILDREN. Esclavos puertas adentro. Las peores formas de trabajo infantil doméstico, 2008. Disponible en www.savethechildren.es/docs/.../Informe_esclavos_puertas_adentro.pdf.

TORRADO MARTíN, Palomino E. y RÁMOS, González A. 2009. "Una aproximación al tráfico y contrabando de personas: el caso diferencial de menores, niños y niñas en España". Revista Atlántida, vol. no I, 37-63.

La inmigración de menores desde la perspectiva de género, 2012. Dilemata ํo 10, 65-84.

UNICEF. El tráfico de personas especialmente de mujeres y niños de África Occidental y Central, 2005. Disponible en http://www.unicef.es/actualidad-documentacion/noticias/el-trafico-depersonas-especialmente-mujeres-y-ninos-en-africa-cen

Sueños de bolsillo. Informe realizado por IFAM, 2010. Fundación Pere Ferrer. Disponible en http://www.unicef.es/sites/www.unicef.es/files/suenos_de_bolsillo.pdf

Trabalho enviado em 03 de outubro de 2015.

Aceito em 05 de dezembro de 2015. 